\title{
Investigation of passenger car using Macpherson strut for suspension system pt.1: Vehicle behaviour variation of time response
}

\author{
Tanti $\mathrm{Ali}^{1{ }^{1,},}$, Rosli Abu Bakar ${ }^{1}$, Gan Leong Meng ${ }^{1}$ and Zarina Amat Jafar ${ }^{1}$ \\ ${ }^{1}$ Faculty of Mechanical Engineering, Universiti Malaysia Pahang, 26600 Pekan, Pahang, Malaysia
}

\begin{abstract}
It has been decade, researchers has been conducting researches on the topics concerning vehicle behavior. Suspension system, driving maneuver and road profile are the particular parameters in order to achieve the aim in vehicle behavior understanding. This paper combined these three criteria by means of using a passenger car equipped with MacPherson strut front suspension undergoes different driving behavior. The objective of this paper is to study the effect of passenger car equipped with MacPherson strut front suspension system vehicle behavior based on different driving maneuvers. For this study, Proton Persona Sedan 1.6 Manual Transmission Base Line was used to investigate the MacPherson strut suspension system. Data were collected using DEWESoft Software. As the velocity and direction varies with time, the vehicle response subjected to stationary excitation, while it varies with different velocity and different type of road. Acceleration, deceleration and bumpy test the suspension mechanism support the weight of the vehicle yet to cushion bumps and holes in the road. It can be concluded that the MacPherson strut suspension system has an effect on not only vehicle behavior but also comfort ride. These findings provide the following insights for future research in suspension vibration in order to optimize the performance of the MacPherson strut suspension system.
\end{abstract}

\section{Introduction}

Road vehicle suspensions producing momentum and guidance forces are essential for driving safety. The driver is controlling these forces during accelerating, braking and steering the vehicles [1]. For a road vehicle, the suspension system isolates the occupants or cargo from severe levels of shock and vibration induced by the road surface. This isolation from road induced shock and vibration also improves the longevity and durability of the vehicle [2].

Just as importantly, the suspension system enables the wheels to maintain contact with the road, assuring stability and control of the vehicle [2]. The suspension system allows the springs and shock absorbers to absorb the energy of the bump, so drivers and passengers can have smooth ride. While doing these two jobs, the suspension system must not allow

* Corresponding author: tanty.ali@gmail.com 
loose, uncontrolled movement of the tire and wheel and must keep the alignment of the tire as correct as possible [3,4]. Fig. 1 shows MAcPherson strut suspension diagram.

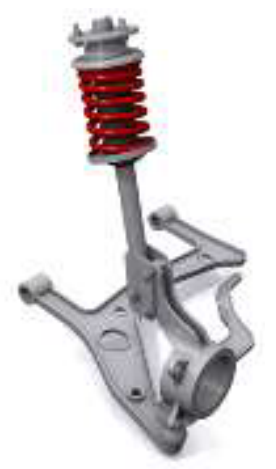

Fig. 1. MacPherson strut suspension.

Earle was the one whom patented MacPherson strut with the idea of locating the lower end of an inclined strut system tangentially with transverse link (or track control arm) and longitudinally by means of the lever arm of the anti-roll bar [2]. Thus, this paper will study the effect of passenger car equipped with MacPherson strut front suspension system vehicle behavior based on different driving maneuvers.

\subsection{Quarter car model}

In general, there are two kinds of approaches in dynamic analysis of a vehicle. The first approach relies on experimental analysis and field test; the second one utilizes computer simulation to conduct a numerical analysis. Fig. 2 shows quarter vibration model in suspension system analysis $[5,6,7]$.

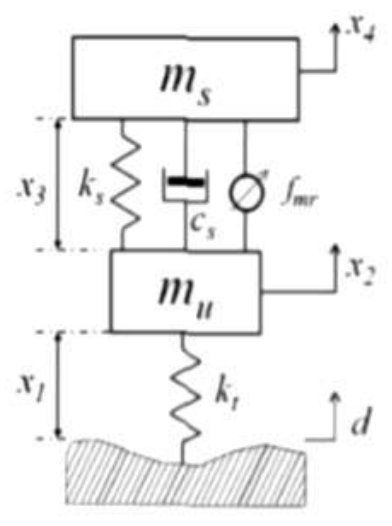

Fig. 2. Quarter car vibration model.

The general equation of motion for any vibration model assigned to vehicle can be defined as follow $[5,6,7,8,9]$ :

$$
[M]\{\ddot{X}\}+[C]\{\dot{X}\}+[K]\{X\}=\{P\}
$$


Where: $[M]$ is mass matrix, $[C]$ is damping coefficient matrix, $[K]$ is stiffness matrix and $\{P\}$ is defined as imposed force on the vehicle by the road.

\section{Design of experiment}

In this study, the experiment is using Proton Persona Sedan 1.6 Manual Transmission Base Line. This test car is equipped with MacPherson strut for the front suspension and multilink with stabilizer for the rear suspension. In addition, the test car is equipped with wire potentiometer, accelerometer, GPS, speed, tire slip angle, gyroscope, rotating wheel sensor that connected to the data acquisition system that has been installed with DEWESoft Software to collect and monitor the data. To check the performance on varying speed ranging from 20 to $120 \mathrm{~km} / \mathrm{h}$ [10]. The gear shifting for the experiment need to follow the maximum speed of each gear (Table 1).

Table 1. Maximum speed of gear.

\begin{tabular}{|c|c|}
\hline Gear & Maximum Speed \\
\hline 1 & $1-20 \mathrm{~km} / \mathrm{h}$ \\
2 & $21-40 \mathrm{~km} / \mathrm{h}$ \\
3 & $41-60 \mathrm{~km} / \mathrm{h}$ \\
4 & $61-80 \mathrm{~km} / \mathrm{h}$ \\
5 & $>81 \mathrm{~km} / \mathrm{h}$ \\
\hline
\end{tabular}

\subsection{Acceleration}

The testing started recording at the static condition (velocity $0 \mathrm{~km} / \mathrm{h}$ ). The pedal is pressed based on the maximum velocity for each gear (Table 1). This test is run for five times to gain the consistent results. This procedure is repeated for each different speed which on paved road $0-60 \mathrm{~km} / \mathrm{h}$ and $0-90 \mathrm{~km} / \mathrm{h}$ whiles the unpaved road is at $0-40 \mathrm{~km} / \mathrm{h}$ and $0-60$ $\mathrm{km} / \mathrm{h}$.

\subsection{Deceleration}

The car is drove until reached $90 \mathrm{~km} / \mathrm{h}$ and the speed is maintained for deceleration 90 $\mathrm{km} / \mathrm{h}$ to $0 \mathrm{~km} / \mathrm{h}$. When the car reached the first cone reference spot (i) as in Fig. 3, the test is started to record and the clutch paddle is pressed. The velocity is cotrolled based on the maximum velocity for each gear (Table 1). As the front tire car reach the second cone reference spot (ii), the clutch paddle is released and the brake pedal is pressed steadily until the car has stopped within the stopping range. The recording is stopped when the final speed is at $0 \mathrm{~km} / \mathrm{h}$. The test is repeated five times. This procedure is repeated for each different speed which on paved road $60-0 \mathrm{~km} / \mathrm{h}$ and $90-0 \mathrm{~km} / \mathrm{h}$ whiles the unpaved road is at $45-0 \mathrm{~km} / \mathrm{h}$ and $65-0 \mathrm{~km} / \mathrm{h}$.

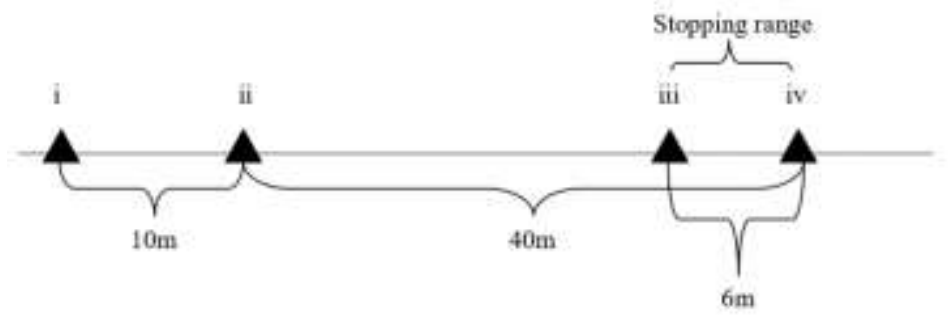

Fig. 3. Cone placement for deceleration testing. 


\subsection{Cornering}

Test car is drove at the inner diameter of the road until reached the speed of $25 \mathrm{~km} / \mathrm{h}$. The driver needs to follow the maximum velocity for each gear (Table 1) that has been set. When the velocity speed reached $25 \mathrm{~km} / \mathrm{h}$ the recording started. Based on Fig. 4, it ended as the car finishes a complete circle of the roundabout which this can be referred on the GPS reading. This test is repeated for five times to ensure the reliability of data gained. The test is repeated at the outer diameter for $40 \mathrm{~km} / \mathrm{h}$ and a $50 \mathrm{~km} / \mathrm{h}$ while at the roundabout with inner diameter is running the initial velocity at $25 \mathrm{~km} / \mathrm{h}$ and $40 \mathrm{~km} / \mathrm{h}$. At the inner diameter, $50 \mathrm{~km} / \mathrm{h}$ velocity is not conducted due to safety purpose which is already been considered.

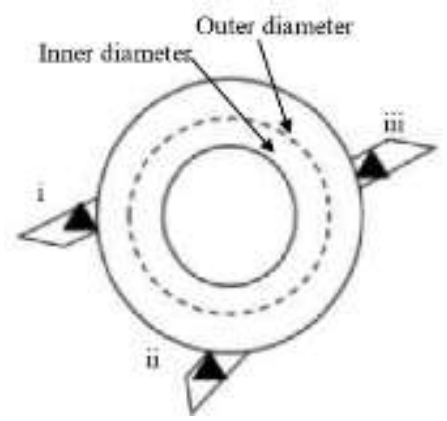

Fig. 4. Cone placement for cornering testing.

\subsection{Bumpy}

The test car is drove until velocity $30 \mathrm{~km} / \mathrm{h}$ is reached and maintained. The driver has to press the pedal based on the maximum velocity for each gear (Table 1). The test is recorded when the front tire reached the first cone spot (i) as in Fig. 5 and ended when the rear tire passed by the second cone (ii). This test is repeated five times and then followed by different constant velocity at $40 \mathrm{~km} / \mathrm{h}$ and $50 \mathrm{~km} / \mathrm{h}$.

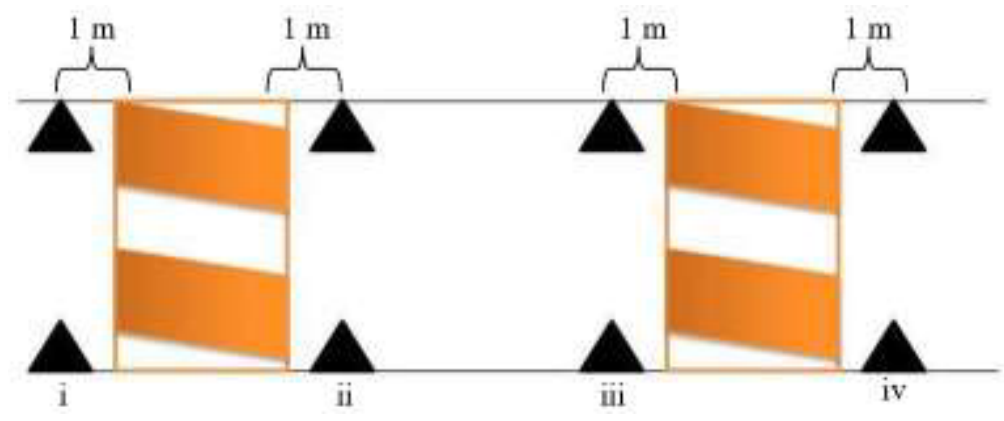

Fig. 5. Cone placement for bumpy testing.

\section{Results and discussion}

\subsection{Variation of time response}

In this part showed the variation of testing velocity in time response. The Fig. 6 until Fig. 9 below showed the relationship of the velocity and direction of the vehicle with the increment of time. These graph clarified the different of the driver driving behavior. The 
pattern of graph displayed the velocity is increased during acceleration (Fig. 6) and decreased during deceleration (Fig. 7).

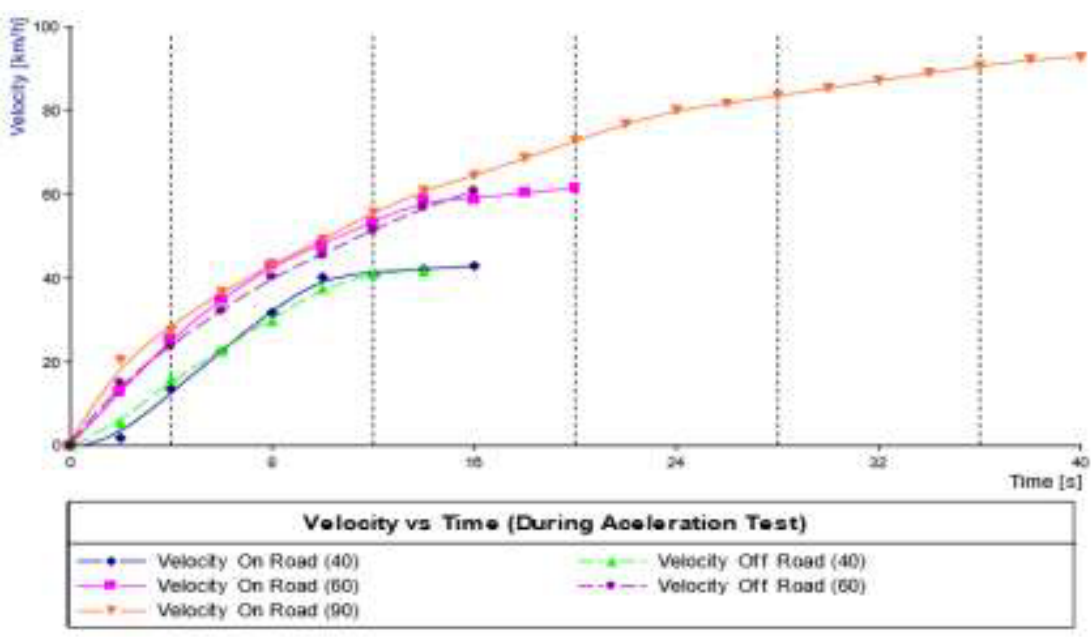

Fig. 6. Graph of Velocity versus Time during the acceleration test.

The time response for the acceleration test is longest during the test $90 \mathrm{~km} / \mathrm{h}$ on road that results in 40 seconds. As for the first acceleration test from $0 \mathrm{~km} / \mathrm{h}$ to $40 \mathrm{~km} / \mathrm{h}$ the testing is only at the 2 nd gear. After the driver reached the speed vehicle at $40 \mathrm{~km} / \mathrm{h}$ the driver need to maintain until 5 seconds. This is for storing data by DEWESoft whereby the results will be constant at final velocity at the end of the testing.

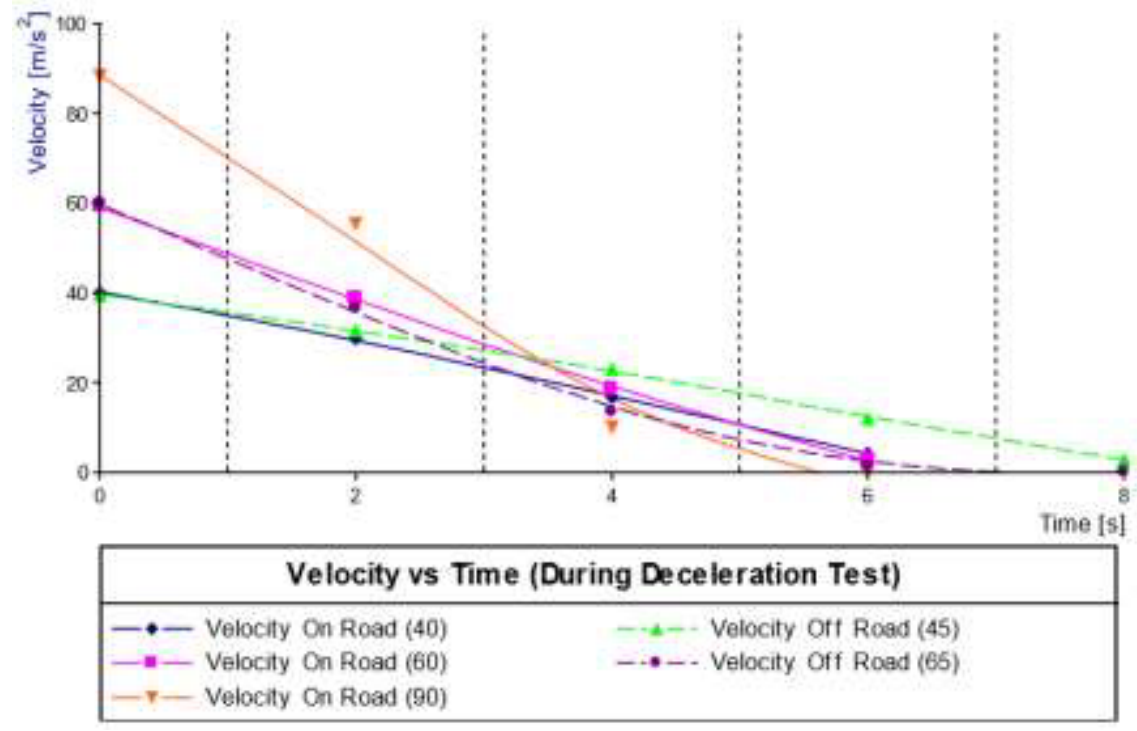

Fig. 7. Graph of Velocity versus Time during the deceleration test.

The longest time taken during the deceleration test on the off road at the speed of 45 $\mathrm{km} / \mathrm{h}$. Due to the off road condition, the tire undergo slip condition. In addition, during the deceleration test, the clutch paddle is pressed when the car is almost to stop in order to 
avoid engine end abruptly. So, this experiment demonstrated that the performance of the suspension system is typically rated as to provide passenger comfort and avoid hitting [11].

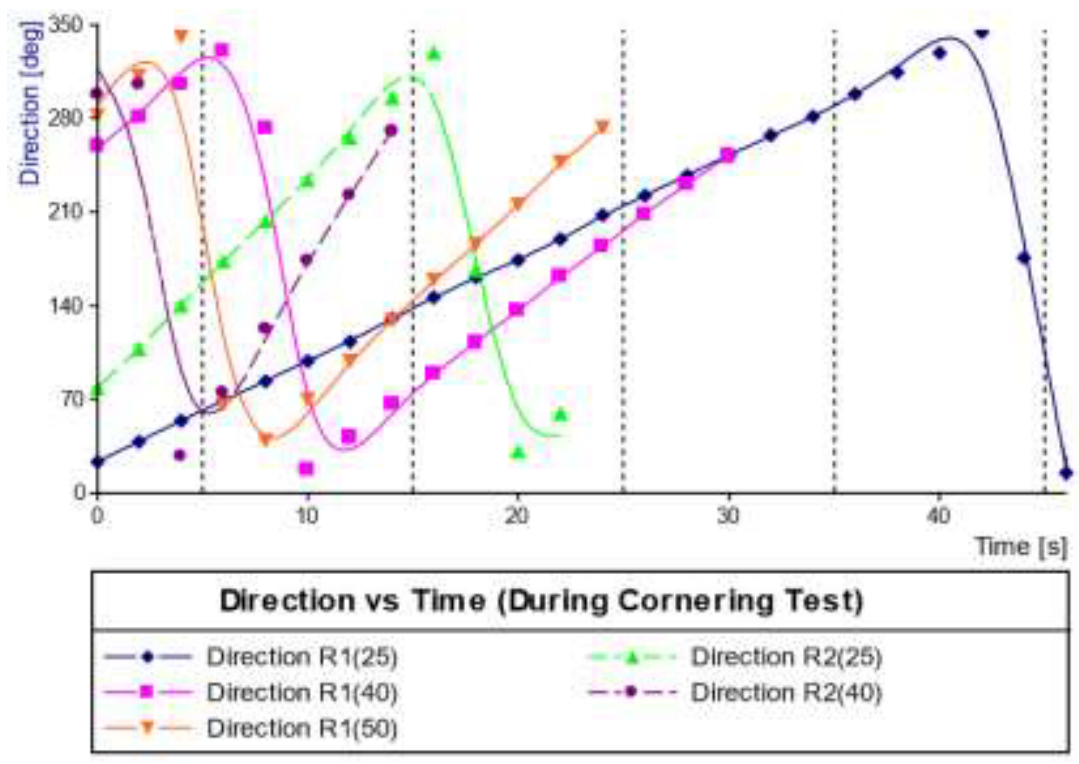

Fig. 8. Graph of Direction versus Time during the cornering test.

The direction of the test car is projectile in the cornering test as shown in Fig. 8, it can be observed that during the testing, test car is at constant speed. The test car results in constant after five second on the bumpy test. Besides, deflections of front suspensions at different speed are shown in Fig. 9. It is assumed that the deflection for right and left wheels is approximately same [7]. Nevertheless, these graphical representation varied concerning on comparison between speed, vehicle acceleration and road roughness effects [9].

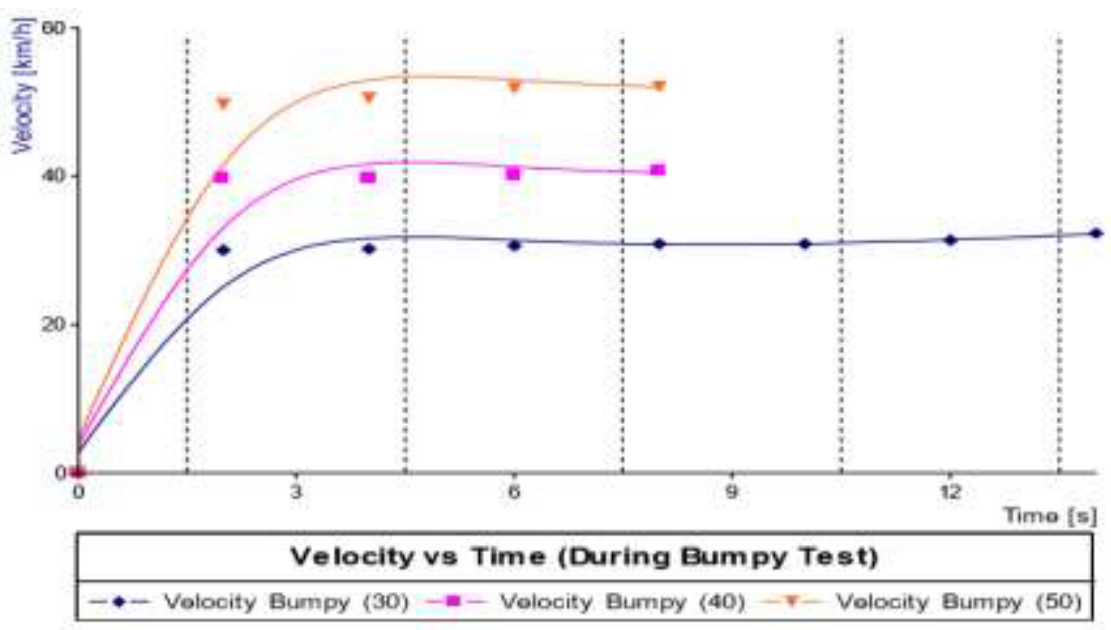

Fig. 9. Graph of Velocity versus Time during the bumpy test. 
As the velocity and direction varies with time, the vehicle response subjected to stationary excitation, while it varies with different velocity and different type of road. Theoretically, throughout acceleration, deceleration and bumpy test the suspension mechanism not only support the weight of the vehicle but it cushioned the bumps and holes in the road. During the steady state cornering the suspension acted to sustain traction between the tires and the road in order to align the wheels [13].

The term "ride comfort" is related to absorption of the energy from road bumps and its dissipation without causing undue oscillation in vehicle. Undue oscillation, also known as vibration, affects the ride quality of the passenger and driver [11]. The term "road handling" relates with vehicle weight transfer from side to side and front to back during cornering and braking action. Thus, a vehicle with good road handling minimize the weight transfer and thus will add in increasing the traction force between vehicle and road surface $[12,13]$.

\section{Conclusions}

Generally, road vehicle suspensions are producing vertical forces in the contact of the tires on the road that provide horizontal contact forces for vehicle propulsion and guidance. These static contact forces existed by dynamic loads due to suspension system behavior based on the unevenness surface. This paper has achieved the objective of showing the pattern of vehicle behavior with different driving maneuvers based on experimental results. It can be concluded that the MacPherson strut suspension system has an effect on not only vehicle behavior but also comfort ride. Conversely, both of ride comfort and vehicle handling requirements are conflicting while designing a vehicle suspension. Consequently, future study can be continued by analyzing the MacPherson strut suspension behavior in order to optimize the standard of ride comfort and vehicle handling under all driving conditions.

The authors would like to thank the Faculty of Mechanical Engineering Universiti Malaysia Pahang (FKM-UMP) final year students Year 2010 for the encouragement to carry this research work. Also the technical staff of FKM-UMP for the assistance during the experimental session using the UMP Test Car.

\section{References}

1. W. Schiehlen, I. Iroz, Uncertainties in road vehicle suspensions, Procedia IUTAM, 13, 151-159, (2015).

2. D. Bastow, G. Howard, J.P. Whitehead, Car suspension and handling, Wallendale: Society of Automotive Engineers Inetrnational, (2004).

3. T.W. Birch, Automotive suspension and steering system, New York: Delmar Publisher, (1999).

4. W.H. Crouse, D.L. Anglin, Automotives mechanics, New York: McGraw-Hill, 658710, (1993).

5. H.B. Dehkordi, Vibration and force analysis of lower arm of suspension system, Universite Du Quebec, (2014).

6. A. Kanjanavapastit, A. Thitinareumit, Estimation of a speed hump profile using quarter car model, Procedia Social and Behavioral Sciences, 88, 265-273, (2013).

7. A. Gupta, V. Rastogi, Effects of various roadconditions on dynamic behavior of heavy road vehicle, Procedia Engineering, 144, 1129-1137, (2016).

8. E. Alvarez-Sanchez, A quarter-car suspension system: car body mass estimator and sliding mode control, Procedia Technology, 7, 208-214, (2013). 
9. M. Hadpe, D.S. Deshmukh, P.M. Solanki, Vibration analysis of a two wheeler (Analytically), International Journal of Innovative Research in Science, Engineering and Technology, 3, 415-421, (2014).

10. M.P. Nagarkar, G.J.V. Patil, R.N.Z. Patil, Optimization of nonlinear quarter car suspension-seat-driver model, Journal of Advanced Research, (2016).

11. A. Mehmood, A.A. Khan, Vibration analysis of damping suspension using car models, International Journal of Innovation and Scientific Research, 9, 202-211, (2014).

12. S.K. Sharma, V. Pare, M. Chouksey, B.R. Rawal, Numerical studies using full car model for combined primary and cabin suspension, Procedia Technology, 23, 171$178,(2016)$.

13. T.Z.S. Ali. Vibration investigation for passenger car front suspension system under various road condition and driving maneuvers. Universiti Malaysia Pahang, (2010). 